\title{
The Spatial-Temporal Distribution and Control Measures Evaluation of Droplets and Aerosol Cloud in Dental Procedures
}

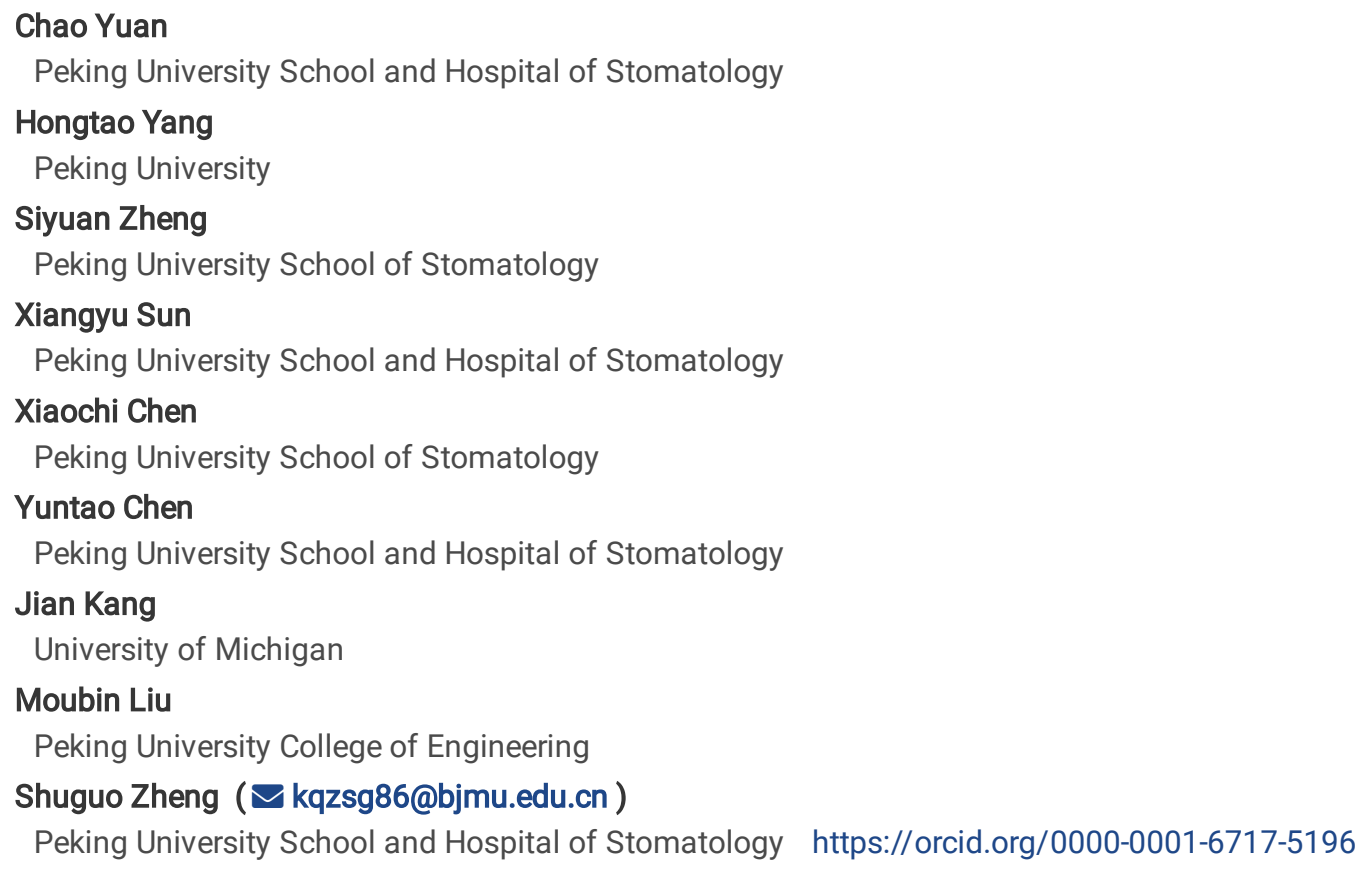

\section{Research Article}

Keywords: Droplets, Aerosol cloud, Infection control, High-speed imaging, laser diffraction, COVID-19

Posted Date: July 7th, 2021

DOl: https://doi.org/10.21203/rs.3.rs-641159/v1

License: @ (1) This work is licensed under a Creative Commons Attribution 4.0 International License. Read Full License 


\section{Abstract}

Background: Droplets and aerosol cloud generating procedures in dentistry can increase the risk of airborne transmission of diseases such as COVID-19. To gain insight into the diffusion of spatters and possible preventive measures, we measured the particle spatial-temporal distribution characteristic and evaluated the effectiveness of the control measures.

Methods: We conducted an experiment to observe the emitted spatters obtained during the simulated dental preparation by using highspeed videography. We measured the particle size distributions by laser diffraction and preliminarily estimated its velocity. We qualitatively and quantitatively described the spatial-temporal distributions of spatters and their control measure effects.

Results: Majority of the dental spatters were small droplets (diameter less than $50 \mu \mathrm{m}$ ). A large number of smallest droplets (diameter less than $10 \mu \mathrm{m}$ ) were generated by high-speed air turbine handpiece. At the oral outlet, the speed of large droplets could exceed $2.63 \mathrm{~m} / \mathrm{s}$, and the speed of aerosol clouds ranged from $0.31-2.37 \mathrm{~m} / \mathrm{s}$. The evolution of the spatters showed that the more fully developed the state, the greater the number of spatters and the wider the contamination range. When the operation mode was moved from the central incisor to the first molar, the spatter direction became increasingly concentrated, and the velocities were enhanced. Larger droplets randomly moved along trajectories and rapidly settled. The aerosol cloud tended to float as a mass that interacted with the surrounding air. The high-volume evacuation could effectively clear away most of the dental spatters. The suction air purifier could change the diffusion direction of the spatters, compress the contamination range, and control aerosol escape into surrounding air.

Conclusions: Our view is that we should combine the 'point' control measure (high-volume evacuation) and 'area' control measure (suction air purifier) to reduce the scope of pollution and prevent the aerosol escape into the surroundings. The study contributes to devising more accurate infection control guidelines, establishing appropriate interventions for different oral treatments, and minimizing the spread of respiratory diseases so that we can reduce cost and achieve the best results when medical resources are limited.

\section{Introduction}

Viral acute respiratory illnesses, ranging from severe acute respiratory syndrome (SARS, 2003) to coronavirus disease 2019 (COVID-19, 2019), are caused by infectious agents. The pathogens responsible for such diseases include but are not limited to influenza virus, rhinovirus, respiratory syncytial virus (RSV), severe acute respiratory syndrome coronavirus (SARS-CoV), and novel SARS-CoV-2 [1-5]. Although we are continuously learning about the transmission modes of these pathogens, current evidence indicates that the primary route of transmission of most acute respiratory agents is through droplets, including short-range direct spray and indirect contact via selfinoculation from fomite sources [6]. However, the available literature[7, 8] shows that aerosols may represent another important pathway for transmission based on cases of SARS-CoV-2 spreading in proximity to asymptomatic individuals [9], as the virus can remain infectious in aerosolized form for hours and on contaminated surfaces for up to days $[1,10]$.

Droplets and aerosol clouds produced during dental procedures are visible to both dentistry workers and patients, and the particulate matter generated by high-powered pneumatic or electric tools (e.g., rotary instruments, the ultrasonic scaler) may contain pathogens originating from the patient's saliva, blood, or respiratory secretions [11-13]. As stated above, these particles are a potential transmission route for infection in light of the possibility that particles of varying sizes could be inhaled through the respiratory tract or contaminate the surfaces of clinical equipment $[12,13]$. Therefore, the number, size, and spatial-temporal distributions of the particles produced by dental procedures must be investigated.

Wells reported that the particle size has a great influence on its trajectory in the air and its spreading range [14, 15]. Large droplets settle to the ground in less than 1 second without significant evaporation, contaminating the immediate vicinity of the source, while small droplets evaporate faster than they settle. Recent work using high-speed imaging to acquire observation data has proven that sneezes do not contain simply large and small droplets; rather, sneezes primarily comprise a turbulent multiphase cloud that entrains surrounding air as well as droplets of varying diameters[16, 17]. Accordingly, dental infection control strategies should be developed based on the spreading modes and distribution characteristics of droplets and aerosol clouds in the air. Nevertheless, relative to the fluid dynamics of violent expirations, the basic mechanisms of particulate matter transmission modes during dental procedures remain poorly understood. The size of the spatter varies from micrometers to millimeters. Various techniques have been leveraged to measure expiratory spatters size distributions, including enumeration on glass slides [18], optical counting [19], aerodynamic droplet sizing [20], interferometric Mie imaging [21], scanning mobility droplet sizing [22], and laser diffraction [23]. However, the size and number distribution of droplet particles produced by dental procedures have rarely been reported.

Though some published articles have provided recommendations of comprehensive precautionary measures [24, 25], bacterial evidencebased infection control measures [26], it's still crucial for advising data-supported selection of infection control measures when treatment is 
too urgent to take prophylactic actions or when resources are limited. To gain insight into the diffusion of spatters and potential preventive measures, we measured the particle spatial-temporal distributions to visualize the original dental surgery procedure and evaluated the effectiveness of the common infection control methods. We believe that studying the spatial-temporal distributions of contaminants and their control methods can contribute to devising more accurate infection control guidelines, establishing appropriate interventions for different oral treatments, and minimizing the spread of respiratory diseases such as COVID-19.

\section{Materials And Methods}

\section{Operatory and equipment setup.}

We conducted an experiment to observe the spatter pattern obtained during the simulated preparation of the central incisor (Operation mode 1, OM1) and the first molar (Operation mode 2, OM2) by using a high-speed air turbine handpiece (HSH) and an ultrasonic scaler (US). The control measures contained a high- and low-volume evacuation (HVE and LVE), and a suction air purifier (SAP).

All dental procedures were conducted in an enclosed dental operatory equipped with a dental unit (KaVo INTRAmatic LUX 325 LHA, KaVo Dental), including a HSH with water spray (T3 SIROBoost, Sirona Dental Systems GmbH), an US (Suprasson P5 Newtron, SATELEC) with a Dentsply 30K slimline scaling tip, a HVE and LVE, and an SAP (AeroVac Pro Dental, E-Maxdent Co., Ltd.). To prevent the airflow from affecting the spatter pattern, we turned off air conditioning and ventilating fans in the operatory operation. The experiments were performed at a relative humidity of $25 \%$ and a temperature of $25^{\circ} \mathrm{C}$.

The mannequin head with a typodont was placed on dental chair to simulate the dental preparation. The Mandibular plane was parallel to the ground ( $60 \mathrm{~cm}$ above the ground). To simulate an oral cavity, we positioned the rubber dam on the typodont to expose teeth and prewetted with water.

We placed a fixed stand with a clamp next to the mannequin. A piece of dental equipment (a HSH or a US) is fixed in 6-o'clock operation mode by the clamp. The power settings and the water dispenser (100\% power and $100 \%$ flow rate) on the dental equipment were identical throughout the experiment. We operated the $\mathrm{HSH}(400,000$ revolutions per minute) and the US (30 kHz) for 20 seconds. The water flow was set at 60.0 milliliters/minute.

We oriented the HVE and LVE $1 \mathrm{~cm}$ from the experimental tooth. We measured the suction rate of the two kinds of evacuations. The time of emptying $1,000 \mathrm{ml}$ water was 12.70 seconds and 38.64 seconds, equating to rates of $78.74 \mathrm{~mL} / \mathrm{second}$ and $25.88 \mathrm{~mL} / \mathrm{second}$ for $\mathrm{HVE}$ and LVE, respectively. We oriented the suction air purifier $10 \mathrm{~cm}$ from the manikin head. The diameter of the suction port is $120 \mathrm{~mm}$. The corresponding clean air delivery rate is $440 \mathrm{~m}^{3} \mathrm{~h}^{-1}$.

\section{Image data processing}

As shown in Fig. 1, we set the oral outlet as the origin of the spatial coordinates and defined the corresponding $x$-, $y$-, and $z$-axes. The spatter pattern was recorded at two observation positions, the $x z$-plane on the back and the $y z$-plane on the side, by high-speed videography (Phantom VEO 410 L, Vision Research Inc.). The position of the LED video light was manually adjusted at each camera site. The diameter of smaller droplets that appeared in the frame was recorded as a pixel.

To make the spatters more visible, the original images were processed at the pixel level by using OpenCV. First, one clear background image was selected from a set of images, and it was successively eliminated from other images as the base. Next, these preliminarily processed images were subjected to three key steps: degradation, histogram equalization, and gamma correction. These steps are responsible for removing signal noise and for clarifying the images to obtain as many details as possible.

\section{Particle size distributions}

A spray droplet measurement system (Spraylink, Linkoptic, CHINA) is used to measure the particle size distributions of spatters by laser diffraction. The focal length of the Spraylink lens used was $100 \mathrm{~mm}$, which allows one to determine particles in a size range of $0.1-2080$ $\mu \mathrm{m}$. A sample frequency configuration of 1 to $10 \mathrm{kHz}$ was used. The volume-based particle size distribution was measured, and the software allows users to calculate the volume mean diameter $\left(D_{4,3}\right)$.

\section{Statistical Analysis}

We qualitatively described the spatial-temporal distributions of the spatters at the oral outlet. The velocity of the presented droplets and aerosol cloud was preliminarily estimated via OpenCV. We selected 120 particles with clear trajectories at the oral outlet on the image and 
recorded their coordinates frame by frame. Due to the determined scale and shutter speed, the coordinates on these images could be plotted as the displacement curve of the particles over time, from which velocity could be obtained. Then, we calculated the mean of the velocity in all directions.

A trial-and-error thresholding process was used to binarize over 3,000 processed images for fully developed clouds at the oral outlet. Based on these binary images, the number of white points appearing in the same pixel was tallied and divided by the quantity of each test images. The heat map of the spatters for every test case measured is generated from the frequency calculated above at each location on the image.

Before any measurements were performed, the conditions were re-established in all cases, with 10 independent repeats per condition on average. The mean and standard deviation of the particle size distribution characteristic parameter in each case were calculated. The Wilcoxon signed-rank test were used to evaluate differences in the size and number distribution.

\section{Results}

The HSH is powered by air turbines, and the US is powered by an electrical current generator. Table 1 reports the velocity components $(u, v$, $w$ and magnitude) of spatters under different working conditions. In the instrument head of the HSH, air is combined with water to generate a high-velocity gas-liquid mixture that exits the handpiece. In OM1, the projection velocity of the aerosol cloud reached $2.22 \mathrm{~m} / \mathrm{s}$, and the direction of the velocity vector was mainly on the horizontal plane $(p<0.05)$. In $\mathrm{OM} 2$, the projection velocity of the aerosol cloud reached 2.37 $\mathrm{m} / \mathrm{s}$, and the direction of the velocity vector was mainly on the coronal plane $(p<0.05)$. For the US, coolant water is ejected from the head of the instrument, producing large droplets and aerosol clouds from the ultrasonic tip with weak airflow. The mean total velocity of large droplets was $2.63 \mathrm{~m} / \mathrm{s}$. The spread of aerosol cloud was generally slow. Specifically, the particle velocity reached $0.31 \mathrm{~m} / \mathrm{s}$ and $0.46 \mathrm{~m} / \mathrm{s}$ in $\mathrm{OM} 1$ and $\mathrm{OM} 2$, respectively.

Table 1 The mean and standard deviation of the spatter velocity under different working condition

\begin{tabular}{|c|c|c|c|c|c|c|c|c|c|c|}
\hline \multirow[t]{2}{*}{ Spatter Type } & \multirow[t]{2}{*}{ Equipment } & \multirow[t]{2}{*}{$\begin{array}{l}\text { Operation } \\
\text { mode }\end{array}$} & \multicolumn{2}{|c|}{$\begin{array}{l}\text { X-axis Velocity } \\
(\mathrm{m} / \mathrm{s})\end{array}$} & \multicolumn{2}{|c|}{$\begin{array}{l}\text { Y-axis Velocity } \\
(\mathrm{m} / \mathrm{s})\end{array}$} & \multicolumn{2}{|c|}{$\begin{array}{l}\text { Z-axis Velocity } \\
(\mathrm{m} / \mathrm{s})\end{array}$} & \multicolumn{2}{|c|}{$\begin{array}{l}\text { Total } \\
\text { Velocity }(\mathrm{m} / \mathrm{s})\end{array}$} \\
\hline & & & Mean & SD & Mean & SD & Mean & SD & Mean & SD \\
\hline \multirow{6}{*}{$\begin{array}{l}\text { Aerosol } \\
\text { cloud }\end{array}$} & $\mathrm{HSH}$ & OM1 & 1.56 & 0.68 & 1.63 & 0.66 & 0.63 & 0.51 & 2.22 & 0.73 \\
\hline & $\mathrm{HSH}$ & OM2 & 0.87 & 0.52 & 0.92 & 0.59 & 1.51 & 0.95 & 2.37 & 0.90 \\
\hline & & & \multicolumn{2}{|l|}{ * } & \multicolumn{2}{|l|}{ * } & \multicolumn{4}{|l|}{ * } \\
\hline & US & OM1 & 0.25 & 0.11 & 0.11 & 0.09 & 0.16 & 0.07 & 0.31 & 0.14 \\
\hline & US & OM2 & 0.14 & 0.09 & 0.31 & 0.18 & 0.27 & 0.15 & 0.46 & 0.21 \\
\hline & & & \multicolumn{2}{|l|}{ * } & \multicolumn{2}{|l|}{ * } & \multicolumn{2}{|l|}{ * } & \multicolumn{2}{|l|}{ * } \\
\hline $\begin{array}{l}\text { Large } \\
\text { droplets }\end{array}$ & US & OM1 & 1.60 & 0.74 & 1.02 & 0.72 & 1.41 & 0.81 & 2.63 & 0.71 \\
\hline
\end{tabular}

* Wilcoxon signed-rank test, $p<0.05$

OM1: Operation mode 1, the simulated preparation of the central incisor. OM2: Operation mode 2, the simulated preparation of the first molar. HSH: high-speed air turbine handpiece. US: ultrasonic scaler.

Fig. 2 shows the evolution of spatters from generation to a fully developed state under different working conditions. Generally, the more fully developed the state is, the greater the number of spatters and the wider the contamination range. When the HSH worked in OM1, the spatter pattern was divided into a sparse upward flow and a relatively dense flow that expands in all directions under the reaction force exerted by the teeth. As shown in Fig. 2A, the former carried small droplets to a high place from the beginning until the end, while the latter, consisting of free-falling droplets and a puff of mist. Fig. $2 \mathrm{C}$ shows that more droplets were produced by the US in OM1 than those produced under other working conditions, and the aerosol cloud was more localized to the vicinity of the head.

As seen in Fig. 2B and Fig. 2D, when the operation mode is moved from the central incisor to the first molar, the direction of the aerosol cloud becomes more concentrated, regardless of the equipment. What is remarkable here is the spatter morphology produced by the HSH in OM2. As shown in Fig. 2B(ii), the spatters bifurcating from the mouth at the beginning tended to approach in the following time and successfully gathered as the water accumulated in the mouth. 
As shown in Table 2 and Fig. 3(A, B), two distinct types of sprays were found, HSH spray $\left(33.44 \mu\right.$ m in volume mean diameter $\left.\mathrm{D}_{4,3}\right)$ and US spray $\left(101.38 \mu \mathrm{m}\right.$ in volume mean diameter $\left.\mathrm{D}_{4,3}\right)$. The concentration histogram indicated that more large droplets were produced by $\mathrm{US}$ spray $(41.62 \%$ in volume fraction of droplet diameter larger than $100 \mu \mathrm{m})$ and that aerosol clouds composed of millions of small droplets were produced by HSH spray (83.84\% in volume fraction of droplet diameter less than $50 \mu \mathrm{m}$ ). The mean number concentrations of HSH

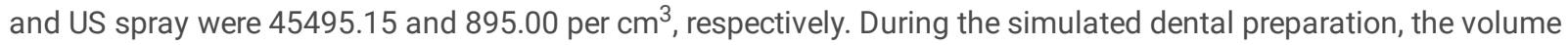

Table 2. The size distribution of the dental spatters under different working condition.

\begin{tabular}{|c|c|c|c|c|c|c|c|c|c|c|c|c|}
\hline \multirow[t]{2}{*}{ Equipment } & \multirow{2}{*}{$\begin{array}{l}\text { Operating } \\
\text { mode }\end{array}$} & \multirow[t]{2}{*}{ Control } & \multicolumn{2}{|c|}{$\mathrm{D}_{4,3}(\mu \mathrm{m})$} & \multicolumn{4}{|c|}{ Number (\%) } & \multicolumn{4}{|c|}{ Volume (\%) } \\
\hline & & & Mean & S.d. & $<10 \mu \mathrm{m}$ & $\begin{array}{l}10- \\
50 \mu \mathrm{m}\end{array}$ & $\begin{array}{l}50- \\
100 \mu m\end{array}$ & $>100 \mu \mathrm{m}$ & $<10 \mu \mathrm{m}$ & $\begin{array}{l}10- \\
50 \mu \mathrm{m}\end{array}$ & $\begin{array}{l}50- \\
100 \mu m\end{array}$ & $>100 \mu \mathrm{m}$ \\
\hline $\mathrm{HSH}$ & Direct & - & 34.44 & 3.13 & 77.46 & 22.48 & 0.06 & 0.00 & 9.56 & 74.28 & 10.69 & 5.47 \\
\hline \multirow[t]{2}{*}{ US } & Direct & - & 101.38 & 8.69 & 0.00 & 78.04 & 19.37 & 2.59 & 0.00 & 23.51 & 34.88 & 41.62 \\
\hline & & & * & & & & & & & & & \\
\hline \multirow[t]{3}{*}{$\mathrm{HSH}$} & OM1 & - & 30.67 & 4.98 & 71.30 & 28.67 & 0.03 & 0.01 & 10.34 & 76.12 & 5.98 & 7.56 \\
\hline & OM2 & - & 14.32 & 0.30 & 87.03 & 12.97 & 0.00 & 0.00 & 23.59 & 76.40 & 0.01 & 0.00 \\
\hline & & & * & & & & & & & & & \\
\hline \multirow[t]{4}{*}{$\mathrm{HSH}$} & OM1 & HVE & 28.62 & 4.32 & 29.59 & 70.25 & 0.16 & 0.00 & 2.66 & 91.29 & 6.05 & 0.00 \\
\hline & OM1 & LVE & 18.48 & 1.37 & 65.94 & 34.06 & 0.00 & 0.00 & 15.38 & 84.38 & 0.24 & 0.00 \\
\hline & $\mathrm{OM} 2$ & HVE & - & & - & - & - & - & - & - & - & - \\
\hline & $\mathrm{OM} 2$ & LVE & 12.45 & 1.15 & 88.27 & 11.73 & 0.00 & 0.00 & 35.39 & 64.61 & 0.00 & 0.00 \\
\hline \multirow[t]{3}{*}{ US } & OM1 & - & 40.05 & 2.63 & 5.15 & 93.80 & 1.03 & 0.03 & 0.24 & 80.70 & 16.26 & 2.79 \\
\hline & $\mathrm{OM} 2$ & - & 32.75 & 1.58 & 21.61 & 78.02 & 0.37 & 0.00 & 1.23 & 90.95 & 7.79 & 0.03 \\
\hline & & & * & & & & & & & & & \\
\hline \multirow[t]{4}{*}{ US } & OM1 & HVE & - & & & & & & & & & \\
\hline & OM1 & LVE & 35.75 & 1.69 & 0.47 & 98.60 & 0.92 & 0.00 & 0.02 & 88.34 & 11.37 & 0.17 \\
\hline & OM2 & HVE & - & & - & - & - & - & - & - & - & - \\
\hline & OM2 & LVE & - & & - & - & - & - & - & - & - & - \\
\hline
\end{tabular}

* Wilcoxon signed-rank test, $p<0.05$

- The number of particles is too low to be detected

OM1: Operation mode 1, the simulated preparation of the central incisor. OM2: Operation mode 2, the simulated preparation of the first molar. HSH: high-speed air turbine handpiece. US: ultrasonic scaler. HVE: high-volume evacuation. LVE: low-volume evacuation. SAP: suction air purifier. $\mathrm{D}_{4,3}$ : volume mean diameter.

means diameter $\mathrm{D}_{4,3}$ of US spatters decreased significantly, from 101.38 to $32.75 \mu \mathrm{m}$. Small droplets (diameter less than $50 \mu \mathrm{m}$ ) dominated the scene. The volume fraction of the small droplets was more than $80 \%$ under different working condition. Most notably, the number fraction of the droplets (diameter less than $10 \mu \mathrm{m}$ ) was $71.30 \%$ in $\mathrm{HSH}-\mathrm{OM} 1$ and $87.03 \%$ in $\mathrm{HSH}-\mathrm{OM} 2$. Compared with OM2, more and larger droplets were detected in OM1 ( $p<0.05)$. As shown in Fig. 3C and Fig. 3D, a large number of spatters escape to the surroundings with the use 
of LVE. Even the HVE could effectively clear away practically all spatters, some smaller droplets still could escape to the surroundings, especially in OM1. The detailed result of the particle size distribution is supplied in Appendix Table 1.

Fig. 4 shows the heat map of spatters under different working conditions. A red pixel shows a 100\% likelihood of a droplet at any time, while a blue pixel points to a $0 \%$ chance. The probabilistic result without intervention is supplementary to Fig. 2 . It is general that the

contamination range of the HSH is wider than that of the US, regardless of what control method is used. The contamination range of the US could be effectively controlled with the use of LVE or HVE, as seen in Fig. 4C and Fig. 4D. Only when a US operated in OM1

under LVE intervention remained a small amount of aerosol clouds. In contrast, as seen in Fig. 4B, the decontamination of the HSH was hard to work except for one case when it operated in OM2 under HVE intervention. Overall, both LVE and HVE are capable of reducing pollution, but HVE has a better performance.

In regard to the SAP, the quantity of spatters out of the mouth remained unchanged. Most of them were removed under the suction caused by negative pressure, so the most important role of the SAP is to change the diffusion direction of the spatters, compress the contamination range, and control aerosol escape into surrounding air. It should be noted that the mottled sputtering marks on the last three pictures in Fig. 4C(ii) indicate that none of the three control methods could dispose of large droplets.

On the whole, larger droplets (with higher mass and momentum) randomly move along trajectories because their inertia is unaffected by the airflow, so they will rapidly settle to the surfaces. In contrast, aerosol clouds tend to float as a mass that interacts with the surrounding air. Because the particles have a small mass, the gravitational effect on the trajectories of the aerosol cloud is limited. Nevertheless, due to the resistance of the surrounding air, the velocity of the aerosol cloud gradually decreases and eventually evaporates into droplet nuclei, which cannot be recorded by high-speed videography. Different control methods must be adopted according to the characteristics of the two kinds of spatters.

\section{Discussion}

The high-speed air turbine handpiece works at the operatory in combination with coolant water sprays and compressed air. When the water spray and compressed air reflect off a surface within the operative area, a large number of droplets and aerosolized particles are formed and escape the air of the dental operatory. These droplets and aerosol clouds can arise both from the coolant water source and directly from the patient's saliva, blood, or respiratory secretions. Previous studies usually concentrated on the bacterial species and particle count measured by using colony-forming units $[27,28]$. However, bacteria that require special media or growth conditions and viral particles are not measured by bacterial culture [29]. Qualitative and quantitative analyses of the composition of dental droplets and aerosol clouds would be extremely difficult, and the composition of the spatter probably varies with each patient and operative site.[11] Therefore, we focus on how to measure the size, number, velocity and spatial probabilistic distributions of the droplets at the oral outlet.

As shown in our study, high-speed imaging can directly record the diffusion process of particles; consequently, we can qualitatively and quantitatively describe the diffusion characteristics. We found that the captured aerosol cloud seems stochastically generated by the flow instability and diversity of the reflection interface. The morphology of clouds evolves in a varied and unpredictable way. Due to a different light reflection on different positions of the drops, the LED-illuminated spatters and corresponding probabilistic calculations consistently belittle the spatial measurement of the spray. However, it is possible to compare the cases systematically and parametrically.

The World Health Organization classification systems categorized host-to-host transmission as droplets or aerosol routes[30]. As shown in our study, most of dental spatters were the small droplets (diameter less than $50 \mu \mathrm{m}$ ) and a large number of smallest droplets (diameter less than $10 \mu \mathrm{m}$ ) were generated by HSH. Large droplets settle and contaminate the immediate vicinity of the oral outlet. Small droplets evaporate faster than they settle. They evaporate and form droplet nuclei or aerosols made of the dried material from the original droplets. These aerosols may contain pathogens. Previous studies indicated that the smaller droplets can remain suspended long enough to reach heights $4-6 \mathrm{~m}$. The droplets $(10 \mu \mathrm{m})$ evaporates in $0.027 \mathrm{~s}$ and would remain suspended meters away from the cougher [31]. Therefore, the spatters generating in dental procedures can increase the risk of airborne transmission of diseases such as COVID-19.

The speeds of spatters ranged from 0.31 to $2.63 \mathrm{~m} / \mathrm{s}$ at the exit in our study. Since the HSH emits a high-velocity gas-liquid mixture, the speed of the resulting aerosol cloud is several times faster than that emitted by the US. For comparison, the speed of the spray directly from the HSH can exceed $12 \mathrm{~m} / \mathrm{s}$, as shown in a recent study [19]. The difference may be due to the presence of various surfaces in the oral cavity, which may transform the spatter pattern or spray volume. In fact, the primary energy of droplets of different sizes is partially absorbed by the saliva, tongue, mucous membrane, or teeth.

The visible droplets fell to the ground within 1 second due to gravity even if their speed reached $2.63 \mathrm{~m} / \mathrm{s}$, while the aerosol cloud with socalled low speed traveled far and floated in the air. This result can be explained by comparing gravity $(F=m g ;$ where $m$ denotes mass and $g$ 
denotes gravitational acceleration) and air drag $(F=6 \pi \eta R U$, limiting for small Reynolds numbers, where $\eta$ represents air viscosity, $R$ the radius of the spherical droplet, and $U$ the flow velocity relative to the droplet). Due to the resistance of the surrounding air, the velocity of the aerosol cloud with less momentum and mass rapidly decreases and finally equals the airflow velocity of the environment. These small droplets are particularly important since they were linked to the aerosolized transmission of SARS-CoV-2 [32].

Our data show that the spatters were more divergent in the anterior area. The spatter directions were more concentrated, and the spatter velocities were enhanced when the operation mode was moved from the central incisor to the first molar, regardless of the equipment. These changes can be explained by the fact that if the water spray source is placed nearer to the oral aperture, the spray would escape from the exit more likely than from the adjacent oral tissue. When the generation source is deep within the oral cavity, the spatter is more concentrated in the exit.

Recent developments associated with the current COVID-19 pandemic have already changed existing protocols regarding personal protective equipment (PPE) and infection control procedures in dental settings [33]. Current recommendations for minimizing COVID-19 transmission include rubber dam isolation, four-handed techniques, and preferential use of high-volume evacuation [34]. Based on our research, we found that the working conditions led to significant differences in the infection control effect. When operating by HSH, almost no spatters can be detected in OM2 under HVE intervention. Therefore, we believe that dental treatment should be safe in the posterior teeth area with HVE. However, we found that due to the dispersed spatter in OM1, all interventions could not completely clear the spatters in the anterior tooth area, which reminds dental practitioners to pay attention to better personal protective equipment and ventilation of dental operatories. When operating by US, regardless of the tooth position, the use of HVE achieved good results, while if HVE cannot be provided, LVE can also play a role in the posterior teeth area. In general, the 'point' control measures (HVE and LVE) cannot completely clear all aerosol. We can assist with the use of 'area' control measure (SAP) to reduce the scope of pollution and control aerosol escape into the surroundings. Although the aerosol clouds produced by HSH are faster $(2.22-2.37 \mathrm{~m} / \mathrm{s})$ and wider in scope, we can use a rubber dam to block liquid in the oral cavity during treatment. The aerosol clouds produced by US are slower $(0.31-0.46 \mathrm{~m} / \mathrm{s})$ and more limited in scope; however, more saliva, blood, and secretions may be brought out due to the lack of rubber dams. The results above give us guidance to choose appropriate methods of intervention so that we can cost least to achieve the best results when medical resources are limited.

It would be preferable to work in a negative pressure environment where clean air can be drawn to the treatment room from less contaminated areas. In most dental clinics, however, it is not possible to work in such an environment. Although the virus load will be diluted by sufficient ventilation $[12,35]$, natural window ventilation will reverse the pollutant trajectory, which causes it to move towards the warning area. Therefore, we recommend active ventilation and SAP, that is, installing an active exhaust system in the treatment room to remove possible pathogens from the air. In this case, 10 minutes would be needed to cycle the air between two patients' appointments, which restricts the use of and access to the dental operatory [36]. Airflow is the most important factor in the persistence of aerosols. As shown in a previous study, in a room with active ventilation, the number of droplets with an average diameter of $5 \mu \mathrm{m}$ halved after 30 seconds, and the total time required for all droplets to disappear was less than 5 minutes [23]. The evidence should be weighed against the benefits of shortened intervals to ensure the economic viability of current care provision models and the accessibility of oral health services.

We assume that because our study was the first, to the best of our knowledge, to observe and model the diffusion process of spatter in dental treatment, the addition of other variables (types of dental equipment, tooth position) will contribute to dissimilar findings. However, the findings from this study have limitations. Although attempts to replicate a real clinical environment are possible, all variables involved in actual clinical practice are difficult to capture through simulation in vitro studies. Previous studies have indicated that computational fluid dynamics is a useful and efficient tool to investigate the airflow and dispersion of particle contaminants in hospital rooms and to evaluate the performance of well-designed ventilation systems and other precautionary measures [37-39]. Referring to theoretical models [16, 17, 31], recent simulations [40-42] of violent expiratory events, and the results of the present study, we plan to customize a numerical solver to simulate the transmission of spatters during dental treatment procedures. We hope the numerical model facilitates the extension of experimental conditions and provides guidelines in a relatively qualitative way in future studies.

\section{Conclusion}

Our view is that we should combine the 'piont' control measure (HVE) and 'area' control measure (SAP) to reduce the scope of pollution and prevent the aerosol escape into the surroundings. The study of the spatial-temporal distributions of contaminants and their control measures can contribute to devising more accurate infection control guidelines, establishing appropriate interventions for different oral treatments, and minimizing the spread of respiratory diseases, allowing us to reduce cost and achieve the best results when medical resources are limited.

\section{Abbreviations}


OM1: Operation mode 1, the simulated preparation of the central incisor.

OM2: Operation mode 2, the simulated preparation of the first molar.

HSH: high-speed air turbine handpiece.

US: ultrasonic scaler.

HVE: high-volume evacuation.

LVE: low-volume evacuation.

SAP: suction air purifier.

\section{Declarations}

Ethics approval and consent to participate: Not applicable

Consent for publication: Not applicable

Availability of data and materials

Extra data is available by emailing Dr. Shuguo Zheng (kqzsg86@bjmu.edu.cn)

Competing interests

The authors declare that they have no competing interests

\section{Funding}

The work was supported by Peking University School and Hospital of Stomatology (grant number: PKUSSNCT-20Y02).

\section{Author Contributions}

C. Yuan, H.T. Yang, S.Y. Zheng, M.B. Liu, S.G. Zheng, contributed to conception, design, data acquisition, analysis, and interpretation, drafted and critically revised the manuscript; X.Y. Sun, X.C. Chen, Y.T. Chen, and J. Kang contributed to conception, design, and interpretation, drafted and critically revised the manuscript. All authors gave final approval and agree to be accountable for all aspects of the work.

Acknowledgements: Not applicable

\section{References}

1. van Doremalen N, Bushmaker T, Morris DH, Holbrook MG, Gamble A, Williamson BN, Tamin A, Harcourt JL, Thornburg NJ, Gerber SI et al: Aerosol and Surface Stability of SARS-CoV-2 as Compared with SARS-CoV-1. The New England journal of medicine 2020, 382(16):15641567.

2. Gandhi M, Havlir D: The Time for Universal Masking of the Public for Coronavirus Disease 2019 Is Now. Open forum infectious diseases 2020, 7(4):ofaa131.

3. Zambon MC, Stockton JD, Clewley JP, Fleming DM: Contribution of influenza and respiratory syncytial virus to community cases of influenza-like illness: an observational study. Lancet (London, England) 2001, 358(9291):1410-1416.

4. Yu ITS, Li Y, Wong TW, Tam W, Chan AT, Lee JHW, Leung DYC, Ho T: Evidence of airborne transmission of the severe acute respiratory syndrome virus. The New England journal of medicine 2004, 350(17):1731-1739.

5. Andersen KG, Rambaut A, Lipkin WI, Holmes EC, Garry RF: The proximal origin of SARS-CoV-2. Nat Med 2020, 26(4):450-452.

6. Tellier R, Li Y, Cowling BJ, Tang JW: Recognition of aerosol transmission of infectious agents: a commentary. BMC Infect Dis 2019, 19(1):101. 
7. Azuma K, Yanagi U, Kagi N, Kim H, Ogata M, Hayashi M: Environmental factors involved in SARS-CoV-2 transmission: effect and role of indoor environmental quality in the strategy for COVID-19 infection control. Environ Health Prev Med 2020, 25(1):66.

8. Beggs CB, Shepherd SJ, Kerr KG: Potential for airborne transmission of infection in the waiting areas of healthcare premises: stochastic analysis using a Monte Carlo model. BMC Infect Dis 2010, 10:247.

9. Anderson EL, Turnham P, Griffin JR, Clarke CC: Consideration of the Aerosol Transmission for COVID-19 and Public Health. Risk Anal 2020, 40(5):902-907.

10. Kramer A, Schwebke I, Kampf G: How long do nosocomial pathogens persist on inanimate surfaces? A systematic review. BMC Infect Dis 2006, 6:130.

11. Harrel SK, Molinari J: Aerosols and splatter in dentistry: a brief review of the literature and infection control implications. Journal of the American Dental Association (1939) 2004, 135(4):429-437.

12. Meng L, Hua F, Bian Z: Coronavirus Disease 2019 (COVID-19): Emerging and Future Challenges for Dental and Oral Medicine. Journal of dental research 2020, 99(5):481-487.

13. Peng X, Xu X, Li Y, Cheng L, Zhou X, Ren B: Transmission routes of 2019-nCoV and controls in dental practice. International journal of oral science $2020,12(1): 9$.

14. WELLS WF: ON AIR-BORNE INFECTION*: STUDY II. DROPLETS AND DROPLET NUCLEl. American Journal of Epidemiology 1934, 20(3):611-618.

15. Wells WF: Airborne Contagion and Air Hygiene. An Ecological Study of Droplet Infections. Airborne Contagion and Air Hygiene An Ecological Study of Droplet Infections 1955.

16. Scharfman BE, Techet AH, Bush JWM, Bourouiba L: Visualization of sneeze ejecta: steps of fluid fragmentation leading to respiratory droplets. Experiments in fluids 2016, 57(2):24.

17. Bourouiba L: Turbulent Gas Clouds and Respiratory Pathogen Emissions: Potential Implications for Reducing Transmission of COVID19. JAMA 2020, 323(18):1837-1838.

18. Duguid JP: The size and the duration of air-carriage of respiratory droplets and droplet-nuclei. The Journal of hygiene 1946, 44(6):471479.

19. Sergis A, Wade WG, Gallagher JE, Morrell AP, Patel S, Dickinson CM, Nizarali N, Whaites E, Johnson J, Addison O et al: Mechanisms of Atomization from Rotary Dental Instruments and Its Mitigation. Journal of dental research 2021, 100(3):261-267.

20. Johnson GR, Morawska L, Ristovski ZD, Hargreaves M, Mengersen K, Chao CYH, Wan MP, Li Y, Xie X, Katoshevski D et al: Modality of human expired aerosol size distributions. Journal of Aerosol Science 2011, 42(12):839-851.

21. Morawska L, Johnson GR, Ristovski ZD, Hargreaves M, Mengersen K, Corbett S, Chao CYH, Li Y, Katoshevski D: Size distribution and sites of origin of droplets expelled from the human respiratory tract during expiratory activities. Journal of Aerosol Science 2009, 40(3):256269.

22. Yang S, Lee GWM, Chen C-M, Wu C-C, Yu K-P: The size and concentration of droplets generated by coughing in human subjects. $J$ Aerosol Med 2007, 20(4):484-494.

23. Somsen GA, van Rijn C, Kooij S, Bem RA, Bonn D: Small droplet aerosols in poorly ventilated spaces and SARS-CoV-2 transmission. Lancet Respir Med 2020, 8(7):658-659.

24. Mascarenhas RE, Pralhad S, Manaktala N: Pan-dentemic: safety considerations for dental surgery in the era of COVID-19. Patient Saf Surg 2021, 15(1):16.

25. Banakar M, Bagheri Lankarani K, Jafarpour D, Moayedi S, Banakar MH, MohammadSadeghi A: COVID-19 transmission risk and protective protocols in dentistry: a systematic review. BMC Oral Health 2020, 20(1):275. 
26. Meethil AP, Saraswat S, Chaudhary PP, Dabdoub SM, Kumar PS: Sources of SARS-CoV-2 and Other Microorganisms in Dental Aerosols. Journal of dental research 2021:220345211015948.

27. Kumbargere Nagraj S, Eachempati P, Paisi M, Nasser M, Sivaramakrishnan G, Verbeek JH: Interventions to reduce contaminated aerosols produced during dental procedures for preventing infectious diseases. Cochrane Database Syst Rev 2020, 10:CD013686.

28. Holloman JL, Mauriello SM, Pimenta L, Arnold RR: Comparison of suction device with saliva ejector for aerosol and spatter reduction during ultrasonic scaling. Journal of the American Dental Association (1939) 2015, 146(1):27-33.

29. Zemouri C, de Soet H, Crielaard W, Laheij A: A scoping review on bio-aerosols in healthcare and the dental environment. PloS one 2017, 12(5):e0178007.

30. Organization WH: Infection Prevention and Control of Epidemic- and Pandemic-Prone Acute Respiratory Infections in Health Care. In., edn.: World Health Organization

2014.

31. Lydia Bourouiba ea: Violent expiratory events: on coughing and sneezing. J Fluid Mech 2014, vol. 745, :pp. $537-563$.

32. Lewis D: Is the coronavirus airborne? Experts can't agree. Nature 2020, 580(7802):175.

33. Estrich CG, Mikkelsen M, Morrissey R, Geisinger ML, loannidou E, Vujicic M, Araujo MWB: Estimating COVID-19 prevalence and infection control practices among US dentists. Journal of the American Dental Association (1939) 2020, 151(11):815-824.

34. Ather A, Patel B, Ruparel NB, Diogenes A, Hargreaves KM: Coronavirus Disease 19 (COVID-19): Implications for Clinical Dental Care. J Endod 2020, 46(5):584-595.

35. Stockwell RE, Ballard EL, O'Rourke P, Knibbs LD, Morawska L, Bell SC: Indoor hospital air and the impact of ventilation on bioaerosols: a systematic review. The Journal of hospital infection 2019, 103(2):175-184.

36. Izzetti R, Nisi M, Gabriele M, Graziani F: COVID-19 Transmission in Dental Practice: Brief Review of Preventive Measures in Italy. Journal of dental research 2020, 99(9):1030-1038.

37. Mendez C, Jose JFS, Villafruela JM, Castro F: Optimization of a hospital room by means of CFD for more efficient ventilation. Energy \& Buildings 2008, 40(5):849-854.

38. Chen C, Zhao B, Cui W, Dong L, An N, Ouyang XJJotRSI: The effectiveness of an air cleaner in controlling droplet/aerosol particle dispersion emitted from a patient's mouth in the indoor environment of dental clinics. 2010, 7(48):1105-1118.

39. Bhattacharyya S, Dey K, Paul AR, R Biswas \% J Chaos S, Fractals: A novel CFD analysis to minimize the spread of COVID-19 virus in hospital isolation room. 2020, 139.

40. Vuorinen V, Aarnio M, Alava M, Alopaeus V, Sterberg M: Modelling aerosol transport and virus exposure with numerical simulations in relation to SARS-CoV-2 transmission by inhalation indoors. Safety Science 2020, 130:104866.

41. Diwan SS, Ravichandran S, Govindarajan R, Narasimha R: Understanding Transmission Dynamics of COVID-19-Type Infections by Direct Numerical Simulations of Cough/Sneeze Flows. Transactions of Indian National Academy of Engineering 2020(39).

42. Pendar MR, Páscoa J: Numerical modeling of the distribution of virus carrying saliva droplets during sneeze and cough. Physics of Fluids 2020, 32(8):083305.

\section{Figures}




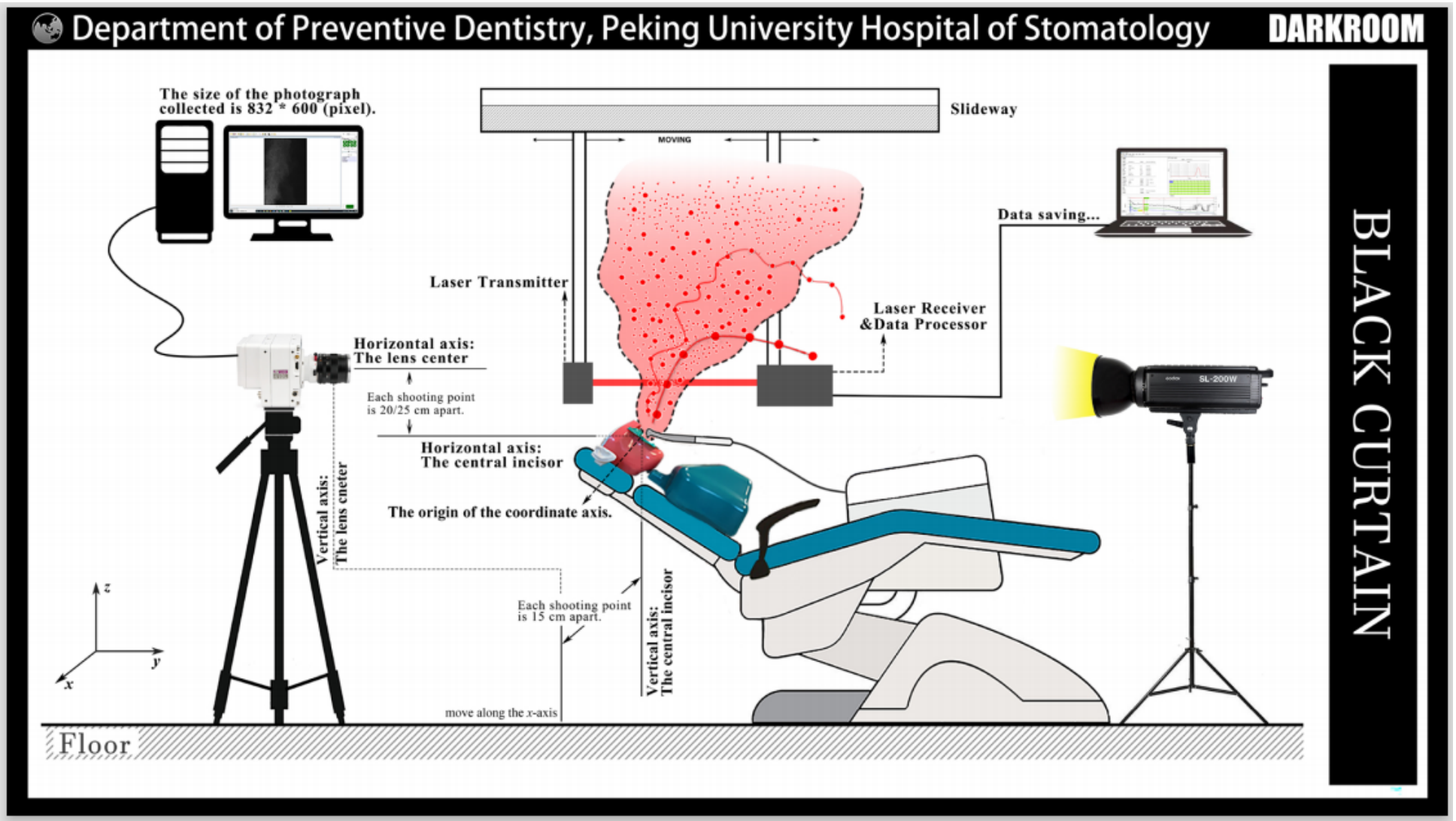

Figure 1

Operatory and equipment setup. Experimental set-up for the visualization of dental spatters by high-speed cameras and the measurement of particle size distributions by laser diffraction. 

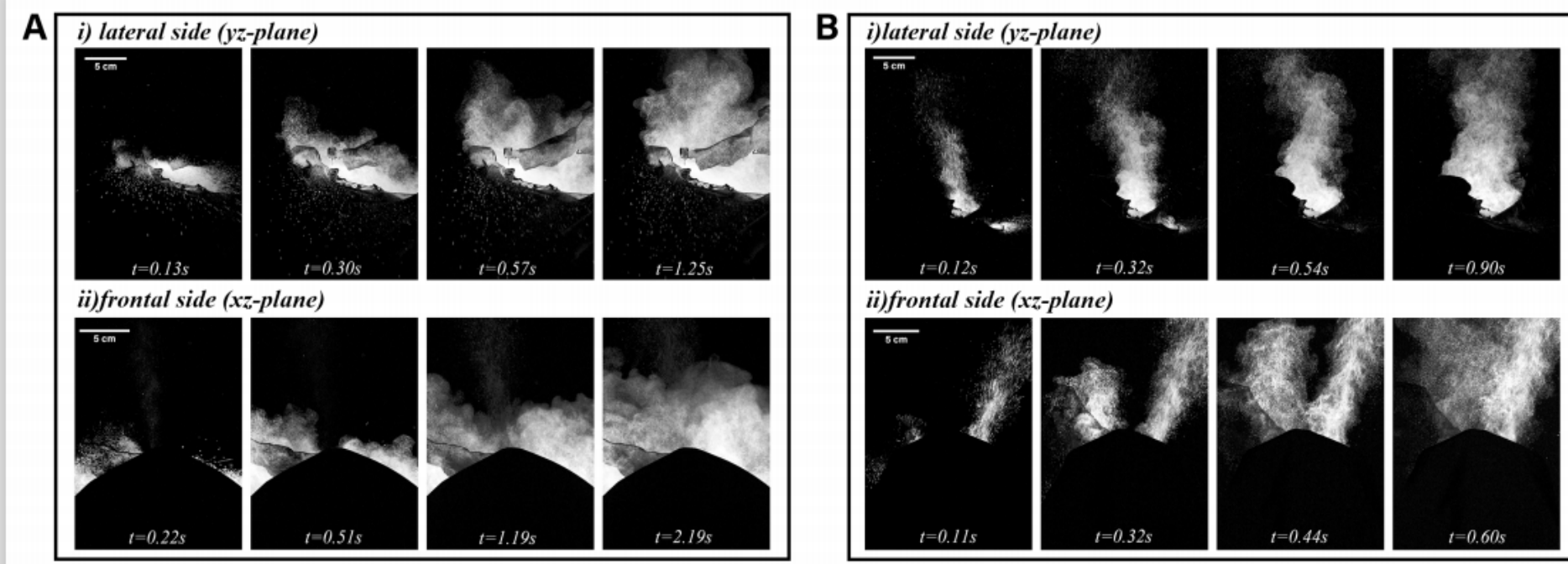

ii)frontal side (xz-plane)
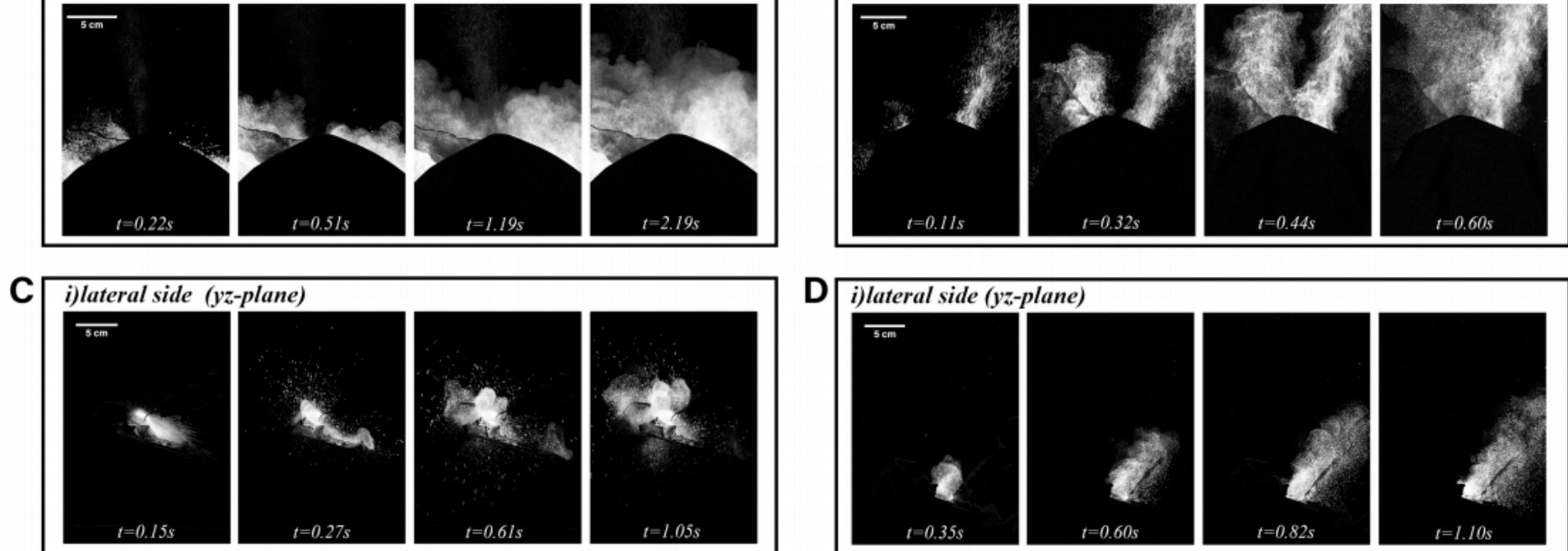

ii)frontal side (xz-plane)
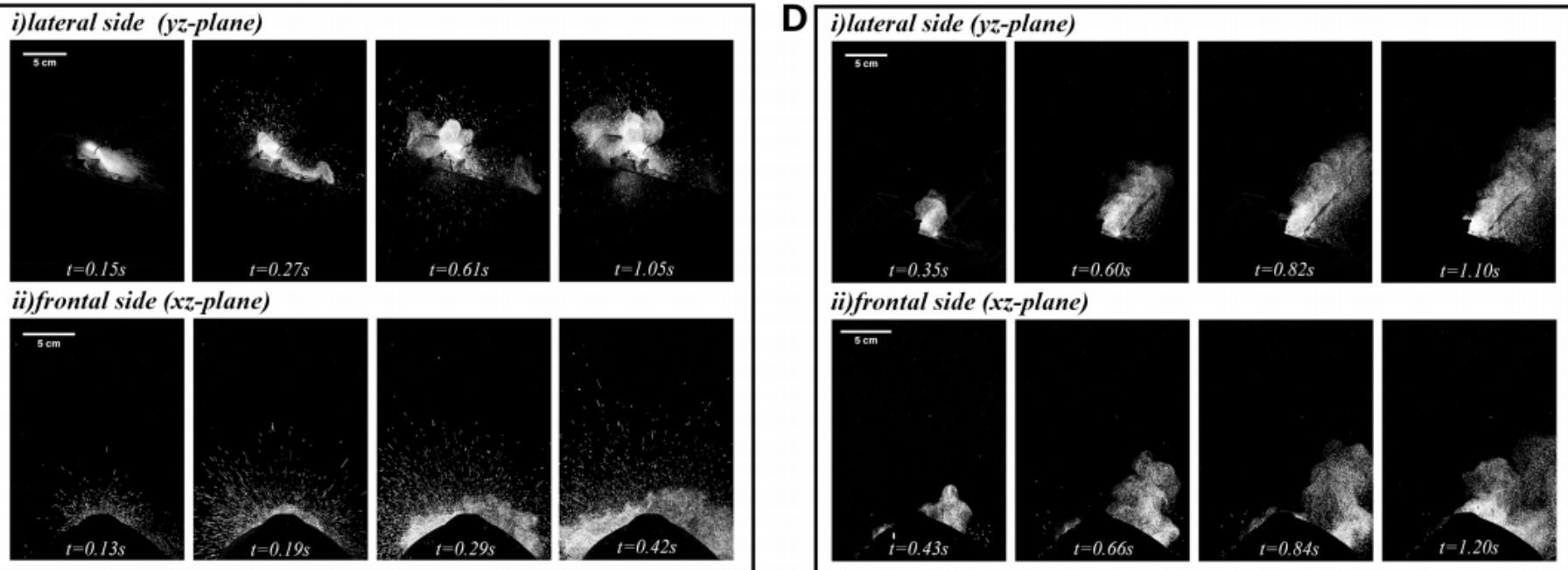

ii)frontal side (xz-plane)
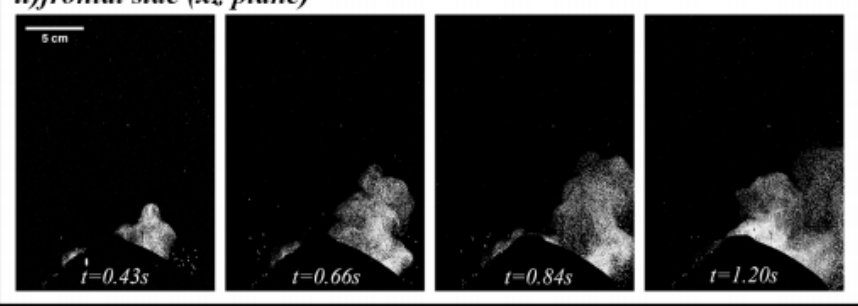

Figure 2

The high-speed image of the spatter spatial-temporal distribution in dental procedures (A) The image of the central incisor preparation with $\mathrm{HSH}$. The spatter pattern was a relatively dense flow that expands in all directions under the reaction force exerted by the teeth. The time of the dental spatter to a fully developed state was $1.25 \mathrm{~s}$ (yz-plane) and $2.19 \mathrm{~s}$ (xz-plane). (B) The image of the first molar preparation with HSH. The spatters bifurcating from the mouth at the beginning tended to approach in the following time and successfully gathered. The time of the dental spatter to a fully developed state was $0.90 \mathrm{~s}$ (yz-plane) and $0.60 \mathrm{~s}$ (xz-plane). (C) The image of the central incisor preparation with US. More droplets were produced than other working conditions, and the aerosol cloud was more localized to the vicinity of the head. The time of the dental spatter to a fully developed state was 1.05s(yz-plane) and 0.42s(xz-plane). (D) The image of the first molar preparation with US. The direction of the aerosol cloud becomes more concentrated. The time of the dental spatter to a fully developed state was 1.10 s(yz-plane) and 1.20s(xz-plane). 

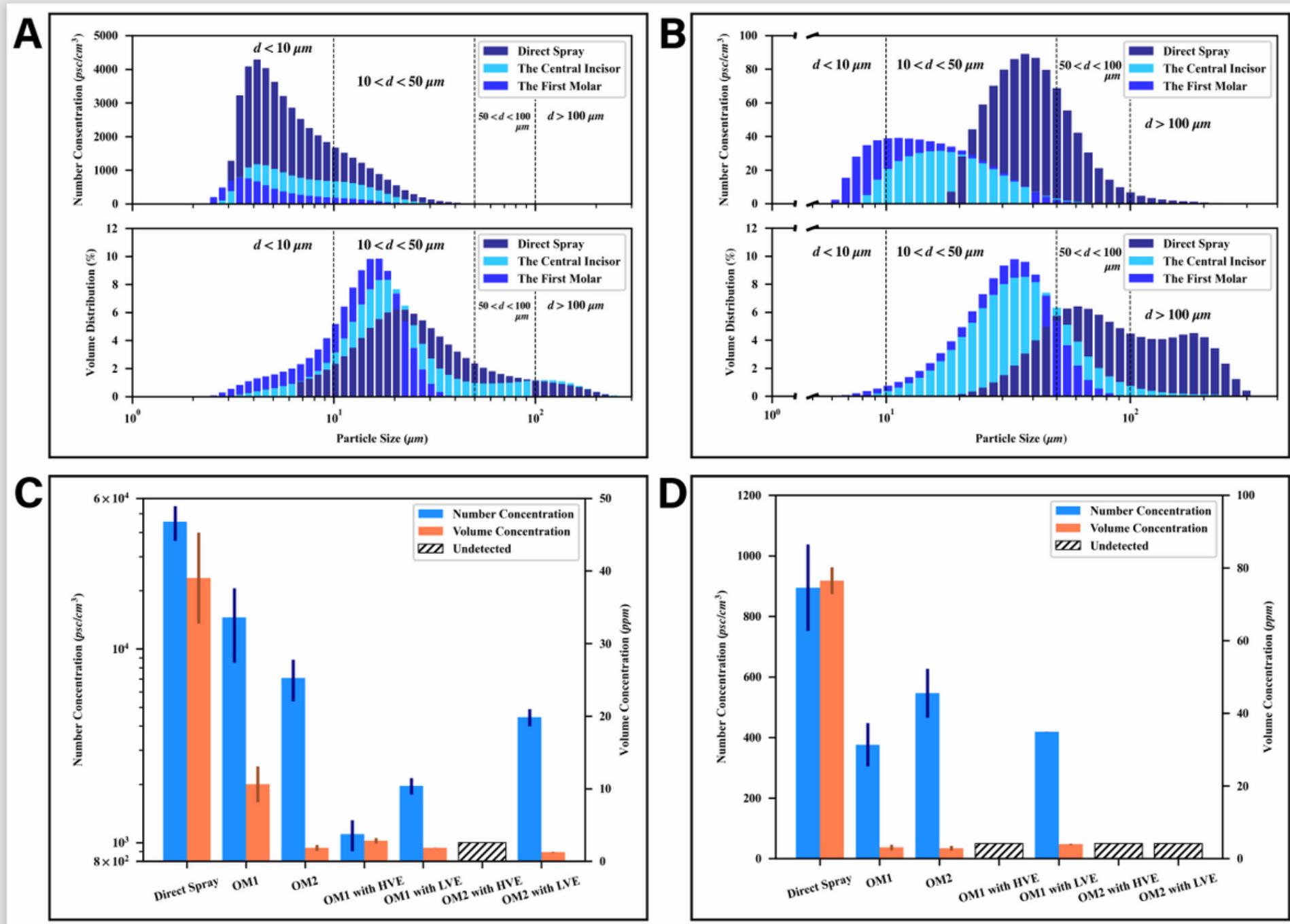

Figure 3

Particle size distribution in dental procedures by laser diffraction. (A) Particle size distribution of HSH. The volume fraction of the small droplets (diameter less than $50 \mu \mathrm{m}$ ) was $86.46 \%$ in OM1 and $99.99 \%$ in OM2. (B) Particle size distribution of US. The volume fraction of the small droplets (diameter less than $50 \mu \mathrm{m}$ ) was $80.94 \%$ in OM1 and $92.18 \%$ in OM2. (C) Characteristic parameters of HSH with or without control measures. HVE could effectively clear away practically all spatters, except in OM1. A large number of small droplets still escape to the air while using the LVE. (D) Characteristic parameters of US with or without control measures. HVE could effectively clear away practically all spatters. LVE only could effectively eliminate spatters in OM2. 


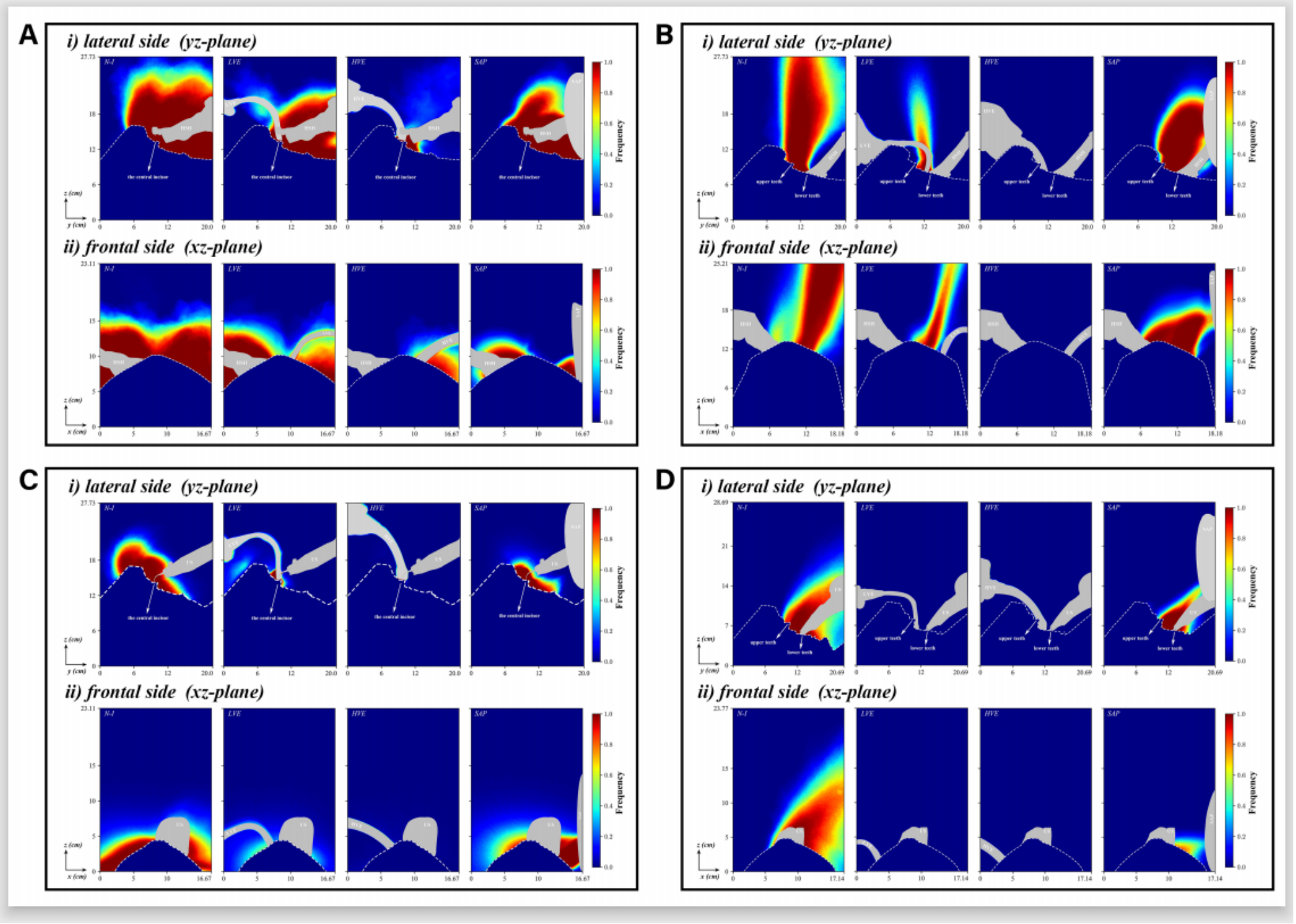

Figure 4

Heat map of spatters produced under different working conditions. A red pixel shows a $100 \%$ probability of a drop at any time, whereas a blue pixel points to a zero probability. (A) HSH operates in OM1 without intervention ( $\mathrm{N}-\mathrm{I}$ ) or with LVE, HVE and SAP intervention. The contamination scope diverges, with none of the interventions clearing all the contaminants. (B) HSH operates in OM2 without intervention $(\mathrm{N}-\mathrm{I})$ or with LVE, HVE and SAP intervention. The contamination scope is concentrated, and almost all interventions work well with the exception of the LVE. (C) US operates in OM1 without intervention (N-I) or with LVE, HVE and SAP intervention. Despite the map result looks good, droplets still exist in the form of radial sputtering no matter what intervention is used. (D) US operates in OM2 without intervention (NI) or with LVE, HVE and SAP intervention. All of the interventions give good performance. The LVE and HVE evacuate water from the mouth while the SAP sucks all the spatters under negative pressure.

\section{Supplementary Files}

This is a list of supplementary files associated with this preprint. Click to download.

- AppendixTable1.docx 